\title{
Oxygen dynamics and porewater transport in sediments inhabited by the invasive polychaete Marenzelleria viridis
}

\author{
Zeljko Jovanovic ${ }^{1}$, Morten Larsen ${ }^{1,2,3}$, Cintia Organo Quintana1 ${ }^{1}$ Erik Kristensen ${ }^{1}$, \\ Ronnie N. Glud ${ }^{1,2,3,4, *}$
}

\author{
${ }^{1}$ Institute of Biology, University of Southern Denmark, Campusvej 55, 5230 Odense M, Denmark \\ ${ }^{2}$ Scottish Association for Marine Science, Dunstaffnage Marine Laboratory, Oban PA37 1QA, UK \\ ${ }^{3}$ Greenland Climate Research Center (CO Greenland Institute of National Resources), Kivioq 2, Box 570, 3900 Nuuk, \\ Greenland \\ ${ }^{4}$ Artic Research Center, C. F. Møllers Allè 8, 8000 Aarhus University C, Denmark
}

\begin{abstract}
The polychaete Marenzelleria viridis is an invasive species and often replaces the native Nereis diversicolor. This shift leads to more reduced conditions and changes in the biogeochemical function of the sediments. By combining imaging techniques for $\mathrm{O}_{2}$ (planar optodes) and irrigation patterns (rhodamine WT and brilliant blue), we investigated the relationship between irrigation and $\mathrm{O}_{2}$ dynamics in burrows of $M$. viridis. The investigated animals shifted between 2 modes of ventilation: ciliary pumping for $77 \%$ of the time and muscular pumping for $23 \%$ of the time. On average, muscular pumping was induced every $0.4 \mathrm{~h}$. During ciliary pumping, oxic water was pumped into blind-ended burrows and into the surrounding sediment, inducing an upward porewater transport of $\mathrm{O}_{2}$-depleted water. This pattern was reversed during muscular pumping. The 2 pumping modes induced oscillating $\mathrm{O}_{2}$ penetration along the burrow wall and along the primary sediment-water interface. The average net downward irrigation rate, including both pumping modes, amounted to $11.1 \times 10^{-3} \pm 2.4 \times 10^{-3} \mathrm{ml} \mathrm{min}^{-1}$. The estimated average oxic sediment volume was $2.1 \pm 0.5 \mathrm{~cm}^{3}$ per burrow, and the burrow-specific $\mathrm{O}_{2}$ consumption was $45.6 \pm 18.1 \mathrm{nmol} \mathrm{min}{ }^{-1} . M$. viridis burrows and the ambient sediment are relatively $\mathrm{O}_{2}$ depleted, with intensified rates of $\mathrm{O}_{2}$ consumption, compared to similar-sized native $N$. diversicolor. The complex $\mathrm{O}_{2}$ dynamics induced a unique microenvironment that must favor meiofauna and microbial communities that are tolerant to oxic-anoxic oscillations or that have the ability to migrate along with the pulsing oxic-anoxic interface.
\end{abstract}

KEY WORDS: Bioirrigation · Oxygen dynamics · Marenzelleria viridis $\cdot$ Planar optode $\cdot$ Rhodamine Resale or republication not permitted without written consent of the publisher

\section{INTRODUCTION}

The invasive polychaete Marenzelleria viridis that originates from the east coast of North America was first reported in Europe around 1980 in the Forth Estuary, Scotland (McLusky et al. 1993). It rapidly spread along the European mainland coasts (Essink \& Kleef 1988) and reached the Danish west coast around 1990 (Jensen \& Knudsen 2005) and the western Baltic Sea in 2004 (Bastrop \& Blank 2006). M. viridis exhibited the classic 'boom-bust' pattern for invasive species at many locations and has now established itself as an integrative part of the coastal infauna in most of northern Europe. The population development has been followed closely in Odense Fjord, Denmark, where the current densities in shal- 
low areas are typically around 100 to 200 ind. $\mathrm{m}^{-2}$, with local maxima of up to 1200 ind. $\mathrm{m}^{-2}$ (Delefosse et al. 2012).

Marenzelleria viridis is a deep-burrowing surface deposit feeder that uses a pair of tentaculate palps to search for food (George 1966) as well as occasional irregular lashing of both palps in the water column for suspension feeding (Dauer et al. 1981). Adults reach a length of $15 \mathrm{~cm}$ and construct up to $40 \mathrm{~cm}$ deep vertical I- or J-shaped burrows with a diameter of $3 \mathrm{~mm}$ in sandy sediment. This polychaete is well adapted to cope with short-term anoxia (Schiedek et al. 1997) and the presence of sulfide (Bochert et al. 1997). M. viridis seems to replace the native fauna dominated by Nereis diversicolor in many areas (Delefosse et al. 2012), and colonized areas rapidly become more reduced and even sulfidic, with cascade effects on the ecosystem function (Kristensen et al. 2011). The mechanisms behind these effects are not clear, but are most likely associated with its unique ventilation patterns.

Marenzelleria viridis only moderately induces particle mixing, and burrows are relatively stationary (Essink \& Kleef 1988, Quintana et al. 2007). The burrows are ventilated to meet metabolic demands by 2 modes, downward ciliary pumping of water (George 1966) and upward muscular pumping (Quintana et al. 2011). Even though ventilation of $M$. viridis burrows is 10 times lower than that of the native Nereis diversicolor, its capacity to drive advective porewater irrigation is much stronger (Kristensen 2001, Quintana et al. 2011). Ciliary-driven ventilation of $M$. viridis is, over time, larger than muscular ventilation, and creates a net downward flow of water that is forced through the burrow walls, irrigating the surrounding permeable sandy sediment (Quintana et al. 2013). Irrigation of $M$. viridis and the associated porewater percolation in combination with stimulated sulfate reduction is hypothesized to increase upward transport of sulfide- and nutrient-rich porewater around the burrow. This apparently leads to increased sulfidic conditions at the primary sediment surface near the burrow, which changes the biogeochemistry of the surrounding sediment and leads to favorable conditions for organisms tolerant to sulfide (Kristensen et al. 2011, Quintana et al. 2013). However, the interaction between irrigation mode, porewater flow and $\mathrm{O}_{2}$ dynamics is not fully understood. Such information is essential for understanding the implications for biogeochemical processes and nutrient regeneration in the surroundings of the burrow.

The overall objective in this study was to resolve in detail the relationship between irrigation patterns and $\mathrm{O}_{2}$ dynamics within and around burrows of Marenzelleria viridis, as induced by animal activities. This was done by combining detailed planar $\mathrm{O}_{2}$ optode measurements with tracer dye studies. The insight gained was used to discuss and evaluate the implications of $M$. viridis ventilation activity for diagenetic processing and microbial ecology in the burrow environment.

\section{MATERIALS AND METHODS}

\section{Sampling}

Sediment, water and individuals of Marenzelleria viridis were collected on several occasions from November 2010 to September 2011. The sampling site was located in the outer part of Odense Fjord on the island of Fyn, Denmark, more specifically at Bregnør Bay $\left(55.48118^{\circ} \mathrm{N}, 10.61002^{\circ} \mathrm{E}\right)$. Salinity varied between 15 and 22 because of variable freshwater discharges from nearby streams. Water depth at the sampling site ranged between 0.5 and $1.1 \mathrm{~m}$.

Bulk sediment was collected at the sampling site and sieved gently through a $1 \mathrm{~mm}$ mesh to collect undamaged specimens of Marenzelleria viridis. The collected specimens of $M$. viridis were stored in a container with in situ seawater and, together with the sieved sediment, were brought immediately to the laboratory. The worms were kept in a container with a layer of sieved sediment $(5 \mathrm{~cm})$ and constantly aerated seawater from the sampling site (temperature $15^{\circ} \mathrm{C}$, salinity 20) for a maximum of $48 \mathrm{~h}$ until the start of the experiments. Subsamples of the sieved sediment were homogenized and transferred to thin measuring aquaria (see 'Experimental setup'). The sediment was composed of organic-poor sand (loss on ignition $=0.67 \pm 0.10 \%, \mathrm{n}=3$ ) with an average particle size of $300 \mu \mathrm{m}$ and porosity of $0.41 \pm 0.03$ $(\mathrm{n}=3)$, similar to what was measured for the same location by Quintana et al. (2007). Permeability estimated from the Carman-Kozeny equation (Rodriguez et al. 2004) was 25.8 D and is therefore considered moderately permeable (Huettel \& Gust 1992). The volume-specific sediment $\mathrm{O}_{2}$ consumption rate $(R)$ was measured to be $0.35 \pm 0.06 \mathrm{nmol} \mathrm{cm}{ }^{-3} \mathrm{~s}^{-1}(\mathrm{n}=4)$ using homogenized, slurried sediment samples. This value was validated against calculations on 5 microprofiles from the $\mathrm{O}_{2}$ images (see below). These calculations resulted in an average $R$ value for the primary interface of $0.39 \pm 0.06 \mathrm{nmol} \mathrm{cm} \mathrm{cm}^{-3} \mathrm{~s}^{-1}(\mathrm{n}=5)$.

To maintain storage of healthy animals and for complementary measurements on unconstrained 
animals in intact sediment, additional sediment cores (i.d. $10 \mathrm{~cm}$ ) were hand cored and transferred to the laboratory. These sediment cores were frozen for $2 \mathrm{~d}$ at $-18^{\circ} \mathrm{C}$ to eliminate all macrofauna and subsequently were submerged in a continuously aerated storage tank (24.5 l) filled with seawater from the sampling site (temperature $15^{\circ} \mathrm{C}$, salinity 20). Cores were left for $1 \mathrm{wk}$ to stabilize before 1 undamaged Marenzelleria viridis specimen was added to each core.

\section{Experimental setup}

The dimensions of the transparent measuring aquaria were $45 \times 25 \times 0.3 \mathrm{~cm}$ (height, length, width) in the lower part and $5 \times 25 \times 3 \mathrm{~cm}$ in the extended upper part containing overlying water (Fig. 1). The back plate of each aquarium was equipped with silicone-filled injection ports ( $2 \mathrm{~mm}$ diameter), arranged in a square matrix, with an inter-port center distance of $1.5 \mathrm{~cm}$. The ports were used for injection of diluted rhodamine WT to visualize and quantify irrigation patterns. A removable front plate was equipped with a transparent $\mathrm{O}_{2}$-sensitive planar optode (Holst \& Grunwald 2001). The planar optode was carefully taped to the inside of each front plate, without catching any air bubbles, before mounting the front plate

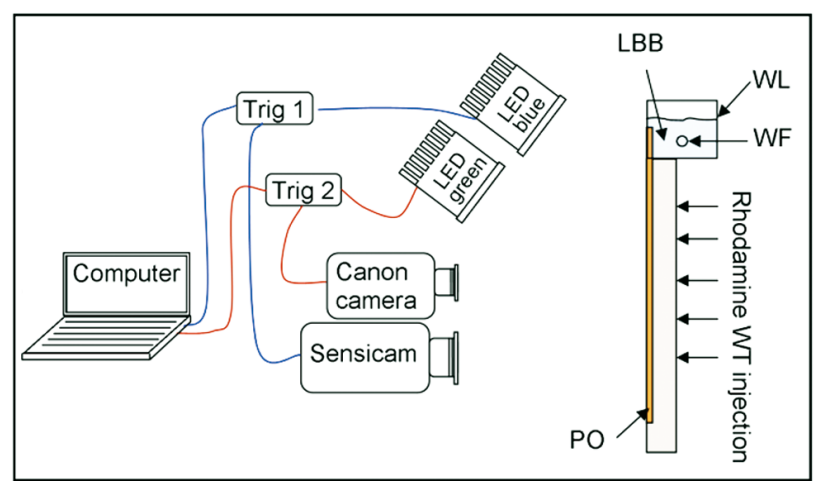

Fig. 1. Experimental setup with 2 camera systems. The Sensicam camera for recording $\mathrm{O}_{2}$ images was connected to the computer together with the excitation light from blue lightemitting diodes (LEDs) (LED blue) via a trigger box (Trig 1). The Canon camera recording of rhodamine WT and lutein and brilliant blue dye displacement was likewise connected to the computer along with green excitation light, also in the form of LEDs (LED green) via a trigger box (Trig 2). Position of the planar optode is indicated on the front of the aquarium (PO). Arrows in the back of the aquarium indicate injection points for rhodamine WT. LBB indicates addition of lutein and brilliant blue dye in the overlying water. Water level is indicated in the upper part of the aquarium (WL), and water flow is enabled by pumping air-saturated seawater through a recirculating system via an inlet (WF) on the aquaria. The measuring aquaria were filled with homogenized sediment and connected to a recirculating reservoir containing 100\% air-saturated seawater from the sampling site (temperature $18^{\circ} \mathrm{C}$, salinity 20). After $24 \mathrm{~h}, 1$ specimen of Marenzelleria viridis was weighed and introduced to each of the aquaria, and specimens were left for another $24 \mathrm{~h}$ to establish burrows. When a burrow was established next to the optode in an aquarium, 2 camera systems were mounted for simultaneous recording of tracer dye displacement and $\mathrm{O}_{2}$ dynamics via the planar optode. Three experiments, 20 h each, were conducted with similar sediment using 3 different aquaria hosting well-defined burrows with lengths of 20 to $25 \mathrm{~cm}$ and diameters of $2 \mathrm{~mm}$ (worm wet wt = 189, 193 and $167 \mathrm{mg})$.

\section{Recording of irrigation patterns}

The displacement of rhodamine WT (Keystone) as well as lutein and brilliant blue (LBB) dye was recorded by a Canon camera (EOS 1000D) placed next to the planar optode imaging system (Fig. 1). The camera was equipped with a prime macro lens (Sigma $50 \mathrm{~mm}$ f2.8 DG Macro) and a $570 \mathrm{~nm}$ longpass filter (Schott OG570). Excitation light was delivered from 4 green light-emitting diodes (LEDs) $(\lambda$ peak 535 nm, Seoul Semiconductor, G42182TXYZ) equipped with $515 \mathrm{~nm}$ longpass excitation filters (Schott OG515). The operation of the LEDs and camera was controlled by the custom-developed software Look@RGB (Larsen et al. 2011). The freeware software ImageJ (http://rsbweb.nih.gov/ij/) was used for all subsequent image processing. To follow porewater displacement, $10 \mu \mathrm{l}$ of diluted rhodamine WT ( $2.74 \mathrm{mg}$ of rhodamine $\mathrm{ml}^{-1}$ ) was injected through the back plate injection ports closest to the burrow. This was supplemented by adding $5 \mathrm{ml}$ of LBB dye $\mathrm{l}^{-1}$ to the overlying water. Rhodamine WT and LBB dye images were taken in the dark every $3 \mathrm{~min}$, alternating with the planar optode imaging.

The fluorescent dye rhodamine WT has an excitation spectrum ( $\lambda$-peak $\sim 555 \mathrm{~nm}$ ) and emission spectrum ( $\lambda$-peak $\sim 580 \mathrm{~nm}$ ) which to some extent overlaps with the excitation spectrum of the coumarin antenna dye ( $\lambda$-peak $\sim 480 \mathrm{~nm}$ ) and emission spectrum of the $\mathrm{O}_{2}$ indicator $(\lambda$-peak $\sim 650 \mathrm{~nm}$ ) (see below). However, with the use of 2 sets of LEDs and applied filter settings, we eliminate any potential optical crosstalk between the rhodamine WT and $\mathrm{O}_{2}$ measurements. As LBB dye is non-fluorescent, there was no interference observed. 
Rhodamine WT is non-toxic and chemically inert (Smart \& Laidlaw 1977) and has low adsorption to sand, $1.75 \times 10^{-4} \mathrm{mg} \mathrm{g}^{-1}$ sediment. During our applications, we initially injected $2.74 \times 10^{-2} \mathrm{mg}$ of rhodamine per point, and maximum adsorption to sediment during our experiment thereby amounted to only $1.1 \%$ of the applied tracer.

\section{Planar optode imaging}

A high-sensitive 12-bit cooled camera (SensiCam, www.PCO.de) equipped with an f1.4/25 mm lens (Tevidon Docter Optics) was used for $\mathrm{O}_{2}$ imaging. The camera was positioned perpendicular to the aquarium next to the excitation light consisting of 4 high-power blue LEDs ( $\lambda$-peak $445 \mathrm{~nm}$, LXHL-LR3C, Luxoen) (Fig. 1). A $470 \mathrm{~nm}$ shortpass filter (blue dichroic color filter, www.uqgoptics.com) was placed in front of the LEDs to eliminate any stray light, while a $590 \mathrm{~nm}$ longpass emission filter (Schott OG590) was placed in front of the camera lens. The operation of the camera and LEDs was synchronized by a computer-controlled trigger box using the custom-developed software Look@Molli (Holst et al. 1998, Holst \& Grunwald 2001). Image processing and profiles extraction were done using the freeware ImageJ (http://rsbweb.nih.gov/ij/). Images were recorded in the dark at 3 min intervals, alternating with the dye imaging described above.

The $\mathrm{O}_{2}$-sensitive planar optode was constructed by knife coating a pre-prepared sensing cocktail onto a transparent, $125 \mu \mathrm{m}$ thin polyester foil (www.goodfellow.com). The cocktail consisted of $1 \% \mathrm{wt} \mathrm{wt}^{-1}$ of the $\mathrm{O}_{2}$ indicator dye platinum (II) meso-tetra (pentafluorophenyl)-porfyrin (PtTFPP) (www.frontiersci.com) and $2 \% \mathrm{wt}^{\mathrm{wt}} \mathrm{t}^{-1}$ of the antenna dye coumarin 545T (www.sigmaaldrich.com) (Mayr et al. 2009) dissolved in a $4 \%$ polystyrene matrix (www.goodfellow.com) using toluene as solvent. PtTFPP has a relatively high dynamic range and long-lived luminescence decay (Khalil et al. 2005). Furthermore, PtTFPP shows excellent photostability and sensitivity in the lower concentration range (Borisov \& Klimant 2007).

$\mathrm{O}_{2}$ quenching was quantified by applying a luminescence lifetime imaging procedure, as described in detail by Holst et al. (1998). Luminescence lifetime images were inferred from 2 well-defined time frames recorded immediately after extinction of the excitation light (Frederiksen \& Glud 2006, Carreira et al. 2013). Lifetime images were converted into $\mathrm{O}_{2}$ concentration images using the modified Stern-
Volmer equation (Klimant et al. 1995), as solved for $\mathrm{O}_{2}$ concentration $\left[\mathrm{O}_{2}\right]$ (Glud et al. 1996):

$$
\left[\mathrm{O}_{2}\right]=\frac{\tau_{0}-\tau}{K_{\mathrm{SV}} \times\left(\tau-\alpha \times \tau_{0}\right)}
$$

Where $\tau$ is the luminescence lifetime at a given $\mathrm{O}_{2}$ concentration, $\tau_{0}$ is the corresponding value in anoxia, $\alpha$ is the non-quenchable fraction of the luminescent signal $(\alpha=0.2)$, and $K_{\mathrm{sv}}$ represents the Stern-Volmer quenching constant. Experimental images were calibrated with a 2-point area average calibration using the luminescence lifetime from areas with known concentration $10 \%$ air saturation from deep anoxic sediment and $100 \%$ air saturation from the water phase). To increase the signal-tonoise ratio, a 16-image average was applied. $\mathrm{O}_{2}$ concentration in the overlying water phase as measured by the planar optode was crosschecked against a separately calibrated point optode (Microx TX3, www.presense.de).

\section{Point optode}

$\mathrm{O}_{2}$ measurements in the specially designed aquaria (Fig. 1) were supplemented by point optode measurements in intact sediment cores. This was done to confirm measurements conducted in the narrow imaging aquaria and to evaluate if confinement affected the behavior of Marenzelleria viridis. A 4channel Firesting optical oxygen meter with retractable needle-type oxygen sensors was fixed on a manually controlled micromanipulator (MM33, www.pyro-science.com) and used for measuring oxygen at the sediment-water interface close to the burrows and at the burrow opening. We cannot exclude that the presence of a sensor in the burrow opening affected animal behavior, but no such responses were observed when placing point sensors close to the burrow during $2 \mathrm{D}$ investigations.

\section{Planar distortion}

When interpreting planar optode images, one must consider that measurements are performed along a flat, $\mathrm{O}_{2}$-impermeable wall that changes the radial diffusion geometry (Wenzhöfer \& Glud 2004, Glud 2008, Meysman et al. 2010). In the case of cylindrical diffusion geometry, the planar optode provides a skewed image of the $\mathrm{O}_{2}$ distribution around the burrow, which leads to increased oxic zones (Oguri et al. 2006). 


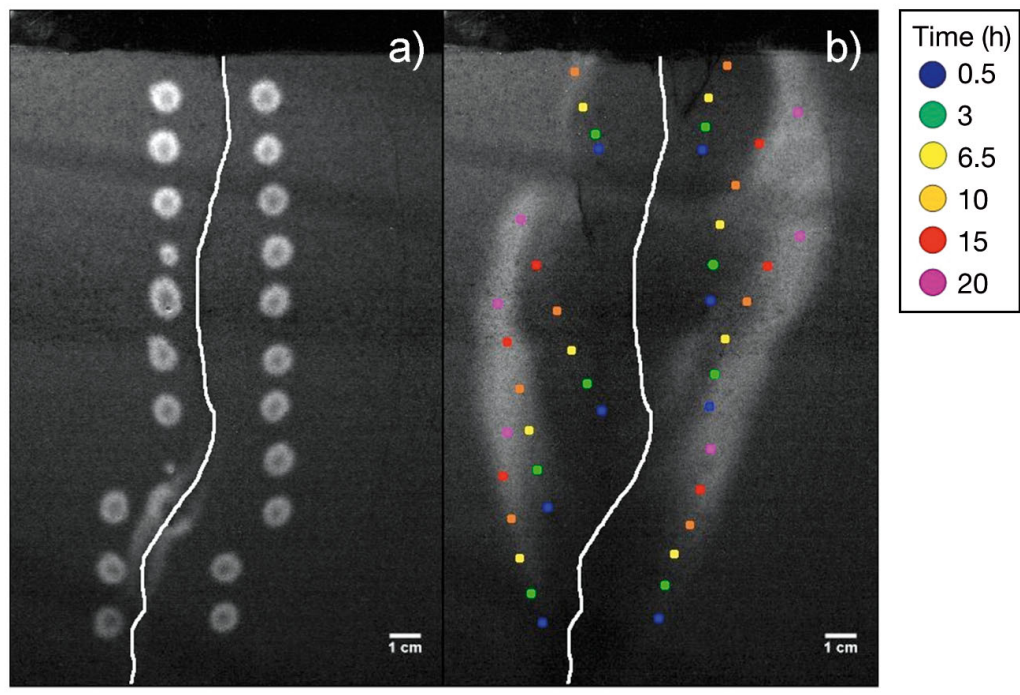

Fig. 2. Start (a) and end (b) images showing net porewater transport along the burrow as visualized via rhodamine WT displacement over time. Colored points were placed in the center of the colored front and represent movement of the front of rhodamine WT over time, showing the direction of porewater movement following irrigation activity of Marenzelleria viridis. The color code used to indicate the respective time points is indicated on the right. White line indicates the position of the burrow

To calculate the volume of oxic sediment around the burrow $\left(V_{\text {ox }}\right)$ in the $0.3 \mathrm{~cm}$ thin experimental aquaria, it was assumed that the observed $2 \mathrm{D} \mathrm{O}_{2}$ images can be directly extended to the third dimension at any given depth. This assumption proved valid by comparing measurements at both sides of the test aquaria in a parallel setup. For each vertical segment, $V_{\text {ox }}$ can then be approximated as $V_{\text {ox }}=(2 \times$ $\left.b \times d-\pi \times r^{2}\right) \cdot \mathrm{L}$, where $\mathrm{b}$ is the apparent $\mathrm{O}_{2}$ penetration distance from the center of the burrow, $d$ is aquarium thickness, $r$ is burrow radius and $L$ is depth of the sediment segment. Total volume of oxic sediment around the burrows is then the sum of all $V_{\text {ox }}$ of the respective segments.

\section{RESULTS}

\section{Irrigation patterns}

The injected rhodamine WT formed distinct colored spots along both sides of the burrow (Fig. 2a). They gradually blurred as they moved upwards and away from the burrow during the $20 \mathrm{~h}$ long incubation (Fig. 2b). The dye moved away from its point of origin by an average of $0.23 \pm 0.03 \mathrm{~cm} \mathrm{~h}^{-1}(\mathrm{n}=3)$ during ciliary pumping in the first $2 \mathrm{~h}$ of the experiment. However, the displacement rate gradually decreased following dispersion of the dye plume.
No movement or slight reversed displacement took place during muscular pumping. Control experiments in aquaria without any Marenzelleria viridis showed that the diffusion of rhodamine WT through the sediment was more than 1 order of magnitude lower than the initial displacement rate observed with polychaetes present.

Apart from the 2 irrigation modes, the direction and rate of rhodamine WT displacement was affected by the position of the worm. Clearly, zones closest to the burrows were more affected and porewater advection was progressively displaced when Marenzelleria viridis moved up and down through the burrow. Irrigation of water into the burrow by ciliary pumping was clearly visualized by the LBB dye added to the overlying water. The LBB dye entered the burrow opening, gradually penetrated and spread away from the burrow (Fig. 3). The dyed sediment area increased initially by $0.09 \mathrm{~cm}^{2} \mathrm{~min}^{-1}$ in the first hour; thereafter, the rate gradually decreased to a minimum of $1.5 \times 10^{-4} \mathrm{~cm}^{2} \mathrm{~min}^{-1}$ after $20 \mathrm{~h}$. Ignoring dilution and assuming that all dyed water originated from the overlying water, a maximum irrigation rate could be estimated from the initial displacement. By multiplying the dyed sediment area with aquarium thickness $(3 \mathrm{~mm})$ and sediment porosity $(0.41 \pm 0.03$ vol $\left.\mathrm{vol}^{-1}\right)$, we obtained a net downward irrigation rate of $11.1 \times 10^{-3} \pm 2.4 \times 10^{-3} \mathrm{ml} \mathrm{min}^{-1}$ in the first $2 \mathrm{~h}$. It is important to realize that the dyed area is amplified compared to unconstrained conditions, but the overall volume of displacement is presumed to be the same (see 'Discussion'). Shifts in irrigation mode were also visible from the LBB dye displacement, as either stagnation or even recession of the dye front (arrows on Fig. 3c). Ciliary pumping occurred for $77 \%$ of the time, as reflected in long periods of progressing dye front, while periods of muscular pumping accounted for the remaining $23 \%$ of the time. Overall, the 3 investigated individuals shifted to muscular pumping $0.42 \pm 0.08$ times $\mathrm{h}^{-1}$.

\section{Oxygen dynamics}

The imaging of $\mathrm{O}_{2}$ dynamics in and around $M a-$ renzelleria viridis burrows by planar optodes clearly showed that oxygenation during ciliary pumping 
a
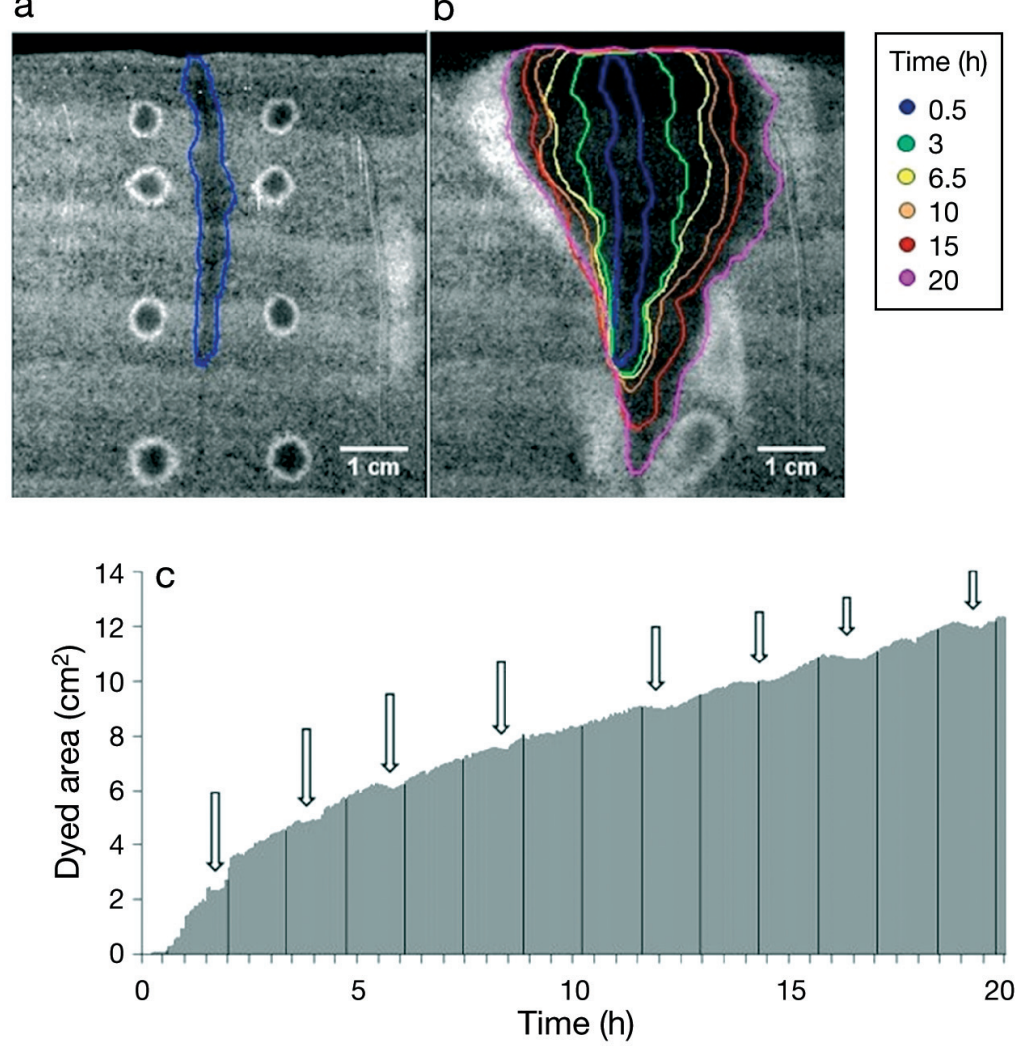

Fig. 3. Porewater migration through the sediment over time as visualized by gradual progression of a dye front (of lutein and brilliant blue, LBB), 0.5 $\mathrm{h}(\mathrm{a})$ and $24 \mathrm{~h} \mathrm{(b)}$ after the introduction of LBB in the overlying water. The color code used to indicate the respective time points is indicated on the right. Increase of the LBB dyed area of the sediment over time (c). Arrows indicate periods of muscular pumping

was most intense close to the surface (Fig. 4a), but periodically ( $15 \%$ of the elapsed time), entire 20 to $25 \mathrm{~cm}$ deep burrows were oxic because of a downward displacement of water driven by intense ciliary pumping. During muscular pumping, this pattern was reversed, with an upward transport of anoxic water (Fig. 4b) to the extent that anoxic plumes occasionally were visible in the overlying water (not shown). The fluctuating $\mathrm{O}_{2}$ levels along the burrows and at the burrow openings were in counter-phase with concentrations and penetration depth of $\mathrm{O}_{2}$ along the primary sediment-water interface in the vicinity of the burrows (Fig. 5). Oxic water pumped into burrows forced percolation of anoxic porewater towards the sediment surface (ciliary pumping, Fig. 4a) which led to reduced $\mathrm{O}_{2}$ penetration at the primary sediment-water interface. When anoxic water was flushed out of burrows (muscular pumping, Fig. 4b), porewater was forced across walls and into burrows, causing deeper penetration of oxic water at the primary sediment-water interface. Consequently, $\mathrm{O}_{2}$ penetration depth in sediment surrounding the burrow opening oscillated according to the mode of pumping. During ciliary pumping, $\mathrm{O}_{2}$ penetration was $2.5 \mathrm{~mm}$, which increased to $4.5 \mathrm{~mm}$ during muscular pumping, as resolved from Fig. 4. Oscillations recorded in the flat aquaria were symmetrical on both sides of the burrow opening and could be detected up to $5 \mathrm{~cm}$ away (not shown). The frequency of these oscillations in $\mathrm{O}_{2}$ penetration depth was about 0.4 oscillations $\mathrm{h}^{-1}$, confirming the value obtained independently by the dye procedure. On average, $\mathrm{O}_{2}$ concentration at the burrow opening oscillated from $\sim 50 \%$ of air saturation during ciliary pumping to $\sim 30 \%$ during muscular pumping (Fig. 5).

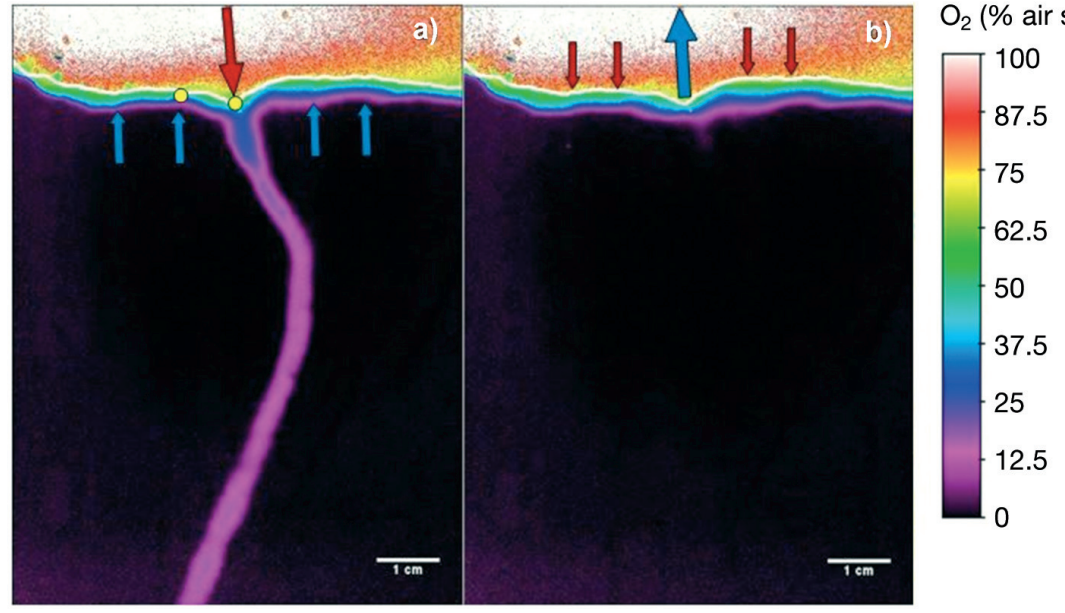

Fig. 4. Changes in $\mathrm{O}_{2}$ concentration in and around the burrow from polychaete activity and oscillations of $\mathrm{O}_{2}$ penetration depth at the sediment-water interface. White line represents sediment-water interface. Red arrows represent direction of movement of oxic water into the burrow while anoxic porewater reaches sediment-water interface during ciliary pumping (a) and blue arrows represent direction of movement of anoxic water out from the burrow while oxic overlying water penetrates deeper into the sediment during muscular pumping (b). Yellow dots indicating selected points from $\mathrm{O}_{2}$ data were extracted from planar optodes images, presented in Fig. 5
NOTE:

Legend was corrected after publication. 


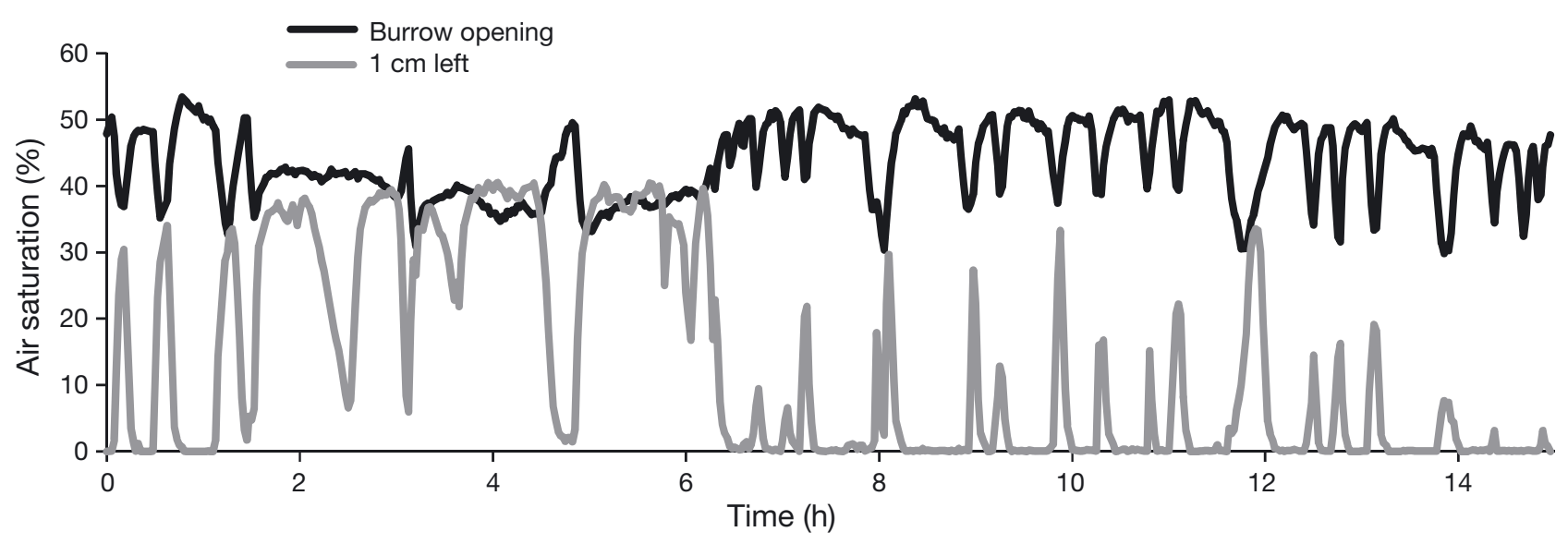

Fig. 5. Extracted $\mathrm{O}_{2}$ concentrations (percentage of air saturation) from the planar optode images at the burrow opening (black line) and $1 \mathrm{~cm}$ away from the burrow opening (grey line)

Test measurements with point optodes in larger sediment cores confirmed the same $\mathrm{O}_{2}$ dynamics pattern, but oscillations were only observed up to $3 \mathrm{~mm}$ away from burrow openings. The dynamics in $\mathrm{O}_{2}$ penetration was therefore amplified by the confinement of burrows in the thin aquaria used for planar optode imaging because of limited sediment volume and the 2D geometry, but the mechanism and temporal pattern were in essence similar to those around the unconstrained burrows.

The continuous $27 \mathrm{~h}$ planar optode imaging of Marenzelleria viridis in the thin aquaria showed that the vertical $\mathrm{O}_{2}$ levels around burrows decrease with depth. Accounting for both modes of pumping and grouping the $\mathrm{O}_{2}$ concentrations resolved by hundreds of images into discrete intervals $(0-1.5$, $1.5-12.5,12.5-37.5,37.5-62.5,62.5-87.5$, and 87.5$100 \%$ of air saturation; Fig. 6), a clear pattern emerges, with $\mathrm{O}_{2}$ levels highest close to the burrow opening and lowest in the deep burrow. At $2 \mathrm{~mm}$ depth, the $\mathrm{O}_{2}$ saturation level was between 37.5 and $62.5 \%$ for $97 \%$ of the time, while the $\mathrm{O}_{2}$ levels were $<1.5 \%$ of air saturation for $84 \%$ of the time at $70 \mathrm{~mm}$ depth. For the rest of the time, the values in the deep sediment generally ranged between 1.5 and $12.5 \%$ of air saturation and only during rare intense ciliary pumping rose above $12.5 \% . \mathrm{O}_{2}$ pumped into the burrow was rapidly used for respiration and oxidation processes along the burrow wall. $\mathrm{O}_{2}$ penetration into the wall of 3 burrows down to $10 \mathrm{~cm}$ using 1294 planar optode images (Fig. 7) was widest in the upper $5 \mathrm{~mm}$ (average $14.3 \pm 0.63 \mathrm{~mm}$ ), decreasing rapidly down to $20 \mathrm{~mm}$ depth and reaching a steady average level of $2.78 \pm 0.89 \mathrm{~mm}$ below, except for a minimum of $1.01 \pm 0.49 \mathrm{~mm}$ at $100 \mathrm{~mm}$ depth. The $\mathrm{O}_{2}$ penetration in the planar setup will be larger than that in

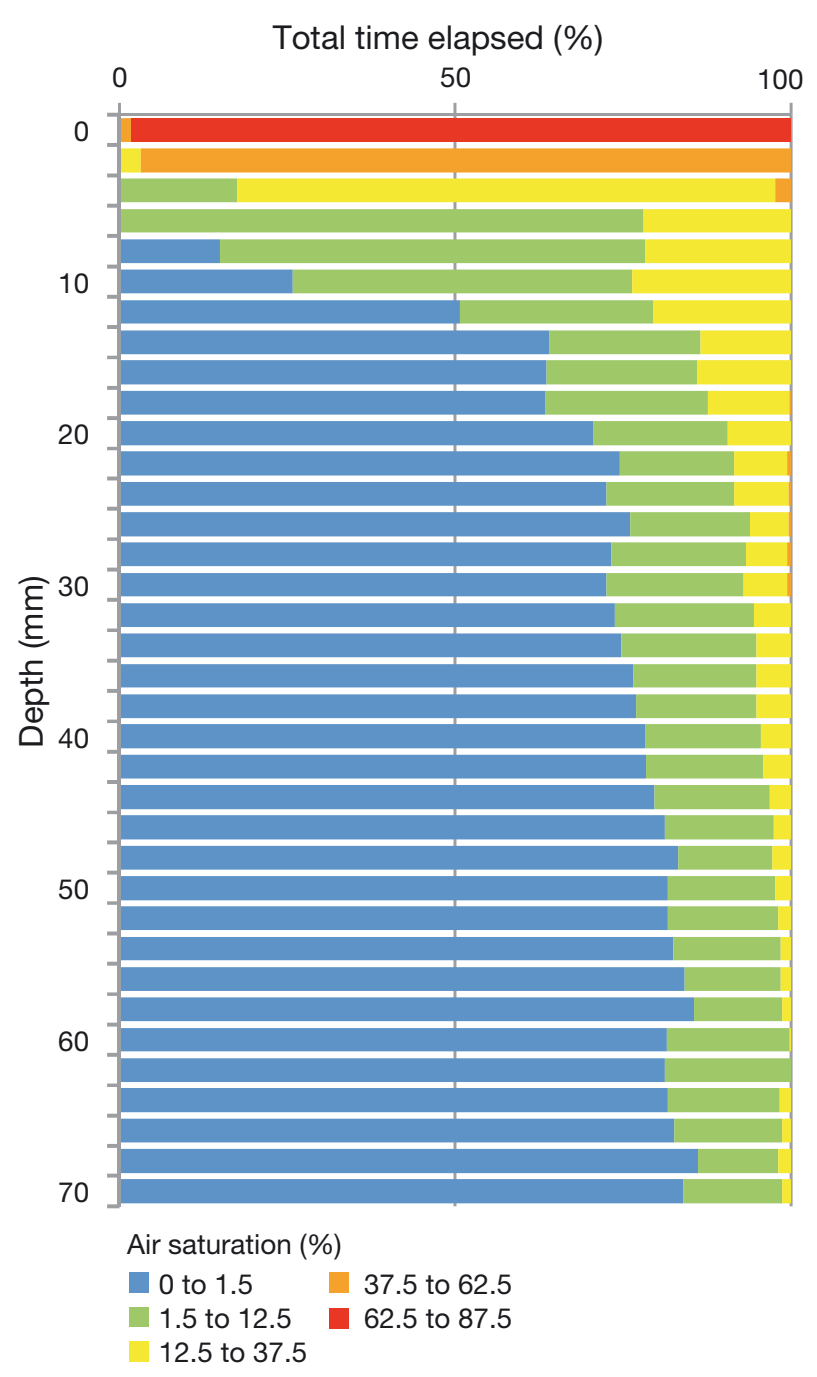

Fig. 6. Changes in percentage of air saturation along the burrow and time the burrow stayed oxygenated as a percentage of total time elapsed. Data were extracted from the planar optode images 


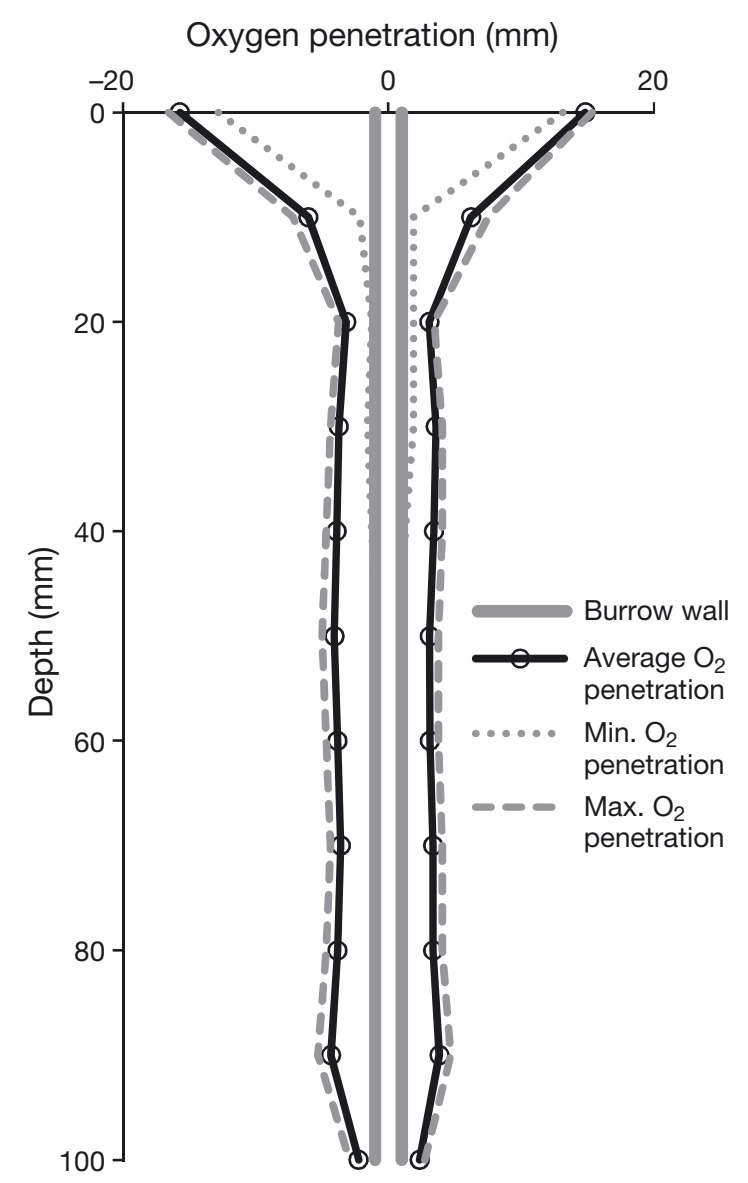

Fig. 7. Average $\mathrm{O}_{2}$ penetration (black line) along the burrow (grey line), down to $10 \mathrm{~cm}$ depth, with minimal (dotted line) and maximal (broken line) $\mathrm{O}_{2}$ penetration. Data were extracted from planar optode images obtained during $27.1 \mathrm{~h}$ of measurements. Measured values could be converted into $\mathrm{O}_{2}$ penetration $(\mathrm{Op})$ for unconstrained burrows with radial transport geometry using a simple relation: $\mathrm{Op}=(2 b d / \pi)^{0.5}-r$, where $b$ represent the apparent $\mathrm{O}_{2}$ penetration depth from the center of the burrow, $d$ is the aquarium thickness of $3 \mathrm{~mm}$ and $r$ is the burrow radius

unconstrained conditions allowing radial transport geometry, but the oxic volume is considered the same. Assuming 0-order $\mathrm{O}_{2}$ kinetics and depthindependent $\mathrm{O}_{2}$ respiration, a simple relation $\mathrm{Op}=$ $(2 b d / \pi)^{0.5}-r$ (where $b$ represents the apparent $\mathrm{O}_{2}$ penetration [Op] depth from the center of the burrow, $d$ represents the aquarium thickness of $3 \mathrm{~mm}$ and $r$ is the burrow radius) could be used to convert the values of Fig. 7 into penetration around an unconstrained burrow. The estimated average volume of oxic sediment around each of the 3 investigated burrows during ciliary pumping was $2.1 \pm 0.5 \mathrm{~cm}^{3}$. Combining the average oxic volume with the volume-specific respiration, which was determined by 2 independent techniques (see 'Materials and methods: Sampling') to be between 0.35 and 0.39 $\mathrm{nmol} \mathrm{cm} \mathrm{cm}^{-3} \mathrm{~s}^{-1}$, provided a burrow-specific $\mathrm{O}_{2}$ consumption of $45.6 \pm 18.1 \mathrm{nmol} \mathrm{m^{-1 }}$.

\section{DISCUSSION}

\section{Irrigation patterns of Marenzelleria viridis}

Transport of solutes in semi-permeable sediment is partly mediated by advection (Santos et al. 2012), and overlying water pumped into blind-ended burrows forces porewater along the path of least resistance towards the surface (Meysman et al. 2006). This was clearly visualized by the dye tracks around Marenzelleria viridis burrows that also reflect the 2 modes of burrow ventilation for this species: muscular- and ciliary-driven water movements (Fig. 3). Ciliary pumping by $M$. viridis, which occurred for $77 \%$ of the time, transports water posteriorly along the body as previously described by Quintana et al. (2011). Water pumped downwards and deep into the burrows by cilia percolates through the burrow walls into the sediment, where $\mathrm{O}_{2}$ is quickly consumed (Fig. 8). The average net irrigation rate of 3 investigated individuals, including periods of both ciliary and muscular pumping, amounted to $11.1 \times$ $10^{-3} \pm 2.4 \times 10^{-3} \mathrm{ml} \mathrm{min}^{-1}$ of water that passed through burrow walls and via the interstitium towards the primary sediment-water interface. This rate compares well with the only other available value of $12 \times 10^{-3} \mathrm{ml} \mathrm{min}^{-1}$ obtained by Quintana et al. (2011) using similar-sized, unconstrained $M$. viridis individuals in sediment from the same location, suggesting that the thin aquaria used here did not have a considerable effect on polychaete behavior. Muscular pumping rates of $M$. viridis could not be quantified directly by the present approach, but planar optode and tracer experiments revealed that the duration of muscular pumping periods account for $23 \%$ of the total elapsed time. This value is similar to the $26 \%$ assessed from $\mathrm{O}_{2}$ fluctuations in the burrow opening of unconstrained polychaetes by Quintana et al. (2011).

Muscular pumping exposes the worm to anoxic porewater from the deeper parts of the burrow and the surrounding sediment for short periods, but Marenzelleria viridis is well adapted to even prolonged events of anoxia (Schiedek 1997, Hahlbeck et al. 2000). It has been suggested that muscular pumping of $M$. viridis is induced to ensure gill cleaning and burrow maintenance (Quintana et al. 2011), as has been observed for Arenicola marina (Volkenborn 


\section{$77 \%$ of time}

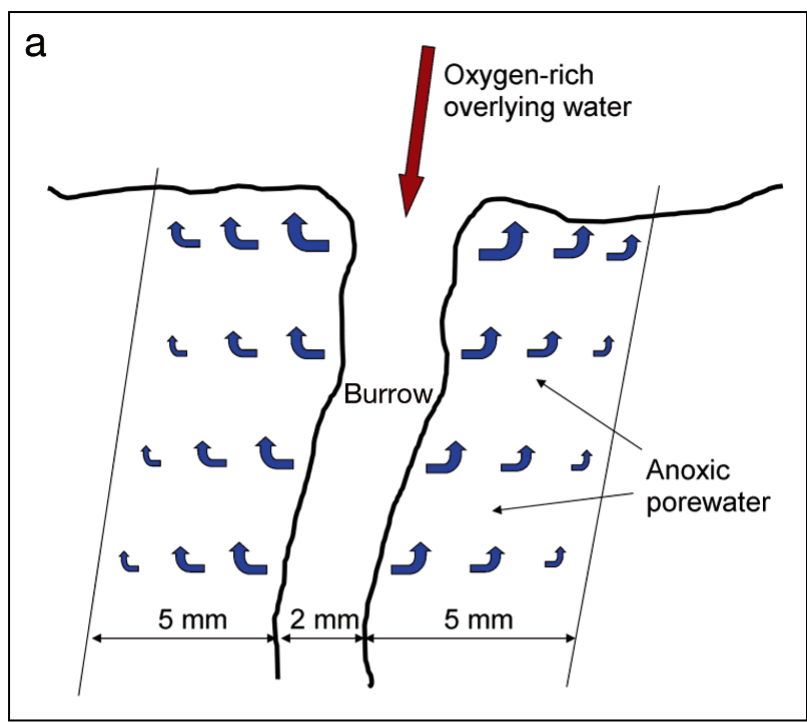

$23 \%$ of time

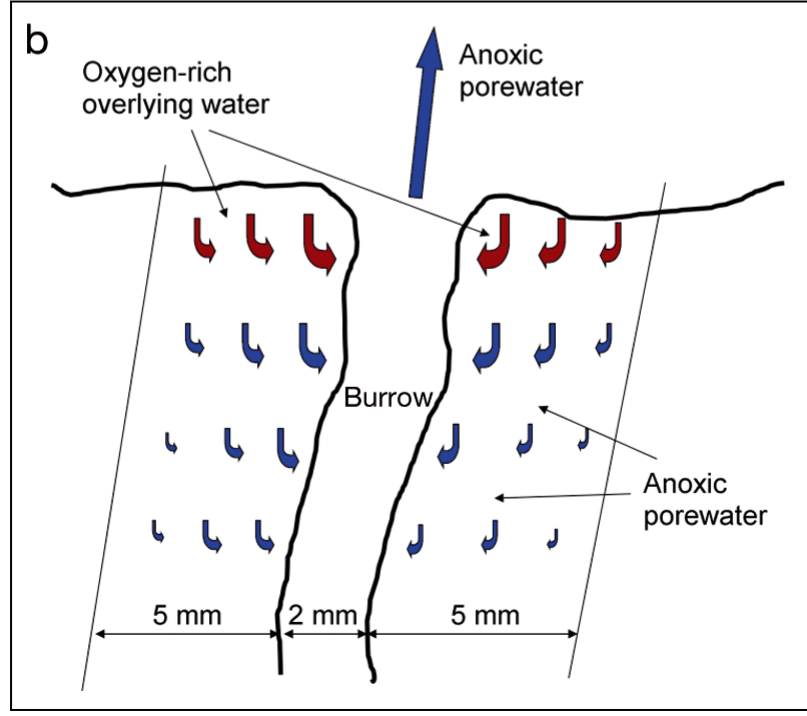

Fig. 8. Marenzelleria viridis. Schematic illustration of irrigation patterns at the burrow opening, with given percentage of ciliary (a) and muscular (b) pumping

et al. 2010). Muscular upward pumping also pushes sulfide- and nutrient-rich porewater out of the burrow opening, while subsequent downward ciliary pumping pushes sulfidic porewater away from the burrow into the surrounding sediment and towards the primary sediment-water interface. The pumping behavior of $M$. viridis is considered to enhance the solute exchange across the sediment-water interface by a factor of 2 to 3 (Quintana et al. 2013). However, natural flow variations in the overlying water could under in situ conditions potentially contribute to ad- vective porewater transport and add to the complexity of fauna-induced advection and $\mathrm{O}_{2}$ dynamics.

\section{Oxygen dynamics within and around the burrow}

Our experiments provide unprecedented details on $\mathrm{O}_{2}$ dynamics within and around burrows of Marenzelleria viridis. The measurements document that $M$. viridis burrow environments are relatively $\mathrm{O}_{2}$ depleted despite the continuous ventilation of the blind-ended burrows. Oxic water only reaches the deep parts of burrows during intense ciliary pumping, and $\mathrm{O}_{2}$ penetrates only a few millimeters into the surrounding sediment. $\mathrm{O}_{2}$ that reaches the $M$. viridis burrow through ciliary pumping is used for polychaete respiration, reoxidation of reduced compounds (sulfide, ammonium, etc.) from anaerobic degradation and aerobic microbial respiration in the surrounding sediment. Only the uppermost first centimeters of the burrow stay oxic for longer periods ( 62.5 to $87.5 \%$ of air saturation for $97 \%$ of the time). Deeper parts of the burrow are mostly anoxic, with only short oxic bursts ( 3 to $12.5 \%$ of air saturation for $4 \%$ of time at $7 \mathrm{~cm} \mathrm{depth)}$.

The present study documents for the first time how the 2 pumping modes of Marenzelleria viridis induce oscillating $\mathrm{O}_{2}$ concentration, not only along the burrow wall (Figs. $6 \&$ 7) but also along the primary sediment-water interface (Fig. 5). During periods of muscular pumping, anoxic water is forced to the surface through the burrow opening and is replenished by anoxic porewater that leads to a downward advection of surface water in the surrounding sediment. This consequently increases $\mathrm{O}_{2}$ penetration depth at the sediment-water interface near the burrow. Conversely, ciliary pumping of oxic water into the burrow, that forces an upward porewater advection, decreases $\mathrm{O}_{2}$ penetration depth at the sedimentwater interface. A similar oscillating $\mathrm{O}_{2}$ penetration depth at the sediment-water interface near $M$. viridis burrows was also observed in unconstrained sediment cores. Here, the hydrological forcing effect reached only $3 \mathrm{~mm}$ radially from the burrow opening compared with up to $5 \mathrm{~cm}$ under constrained conditions in narrow aquaria.

Similar oscillation of $\mathrm{O}_{2}$ concentration around burrows at the sediment-water interface because of the bidirectional pumping of water was observed in the much larger polychaete Arenicola marina (Volkenborn et al. 2010). Burrow ventilation by A. marina induced highly dynamic redox oscillations and dramatic changes in porewater chemistry on a scale of 
minutes (Woodin et al. 2010). However, A. marina is orders of magnitude larger than Marenzelleria viridis and is capable of much higher pumping rates; for example, the $11.4 \pm 3.7 \mathrm{~g}$ wet wt animals studied by Volkenborn et al. (2010) had average pumping rates of $1.2 \mathrm{ml} \mathrm{min} \mathrm{m}^{-1}$ in sediment with similar permeability. Nevertheless, the present study documents that even small polychaetes like $M$. viridis can induce similar and significant effects but on a smaller scale.

The estimated maximum oxic sediment volume of $2.1 \pm 0.5 \mathrm{~cm}^{3}$ per burrow during ciliary pumping in thin aquaria obviously ignores the effect of confinement and obstructed radial geometry. However, we are confident that the results are robust for unconstrained Marenzelleria viridis burrows in sandy sediment, since the irrigation patterns matched that of similar-sized unconstrained polychaetes (Quintana et al. 2011). Accordingly, the net outcome of solute transport is controlled by the force driving irrigation irrespective of planar or radial geometry (Frederiksen \& Glud 2006). Thus, we can calculate that it would take 1833 burrows of $M$. viridis to match the $3850 \mathrm{~cm}^{3} \mathrm{~m}^{-2}$ oxic volume at the sediment-water interface not affected by irrigation. With $M$. viridis abundance in Odense Fjord of 100 to 200 ind. $\mathrm{m}^{-2}$ (local maximum of 1200 ind $\mathrm{m}^{-2}$ ) (Delefosse et al. 2012), M. viridis burrows typically increase the oxic volume of the sediment by only 6 to $11 \%$, with an occasional maximum of $65 \%$. The volume of oxic sediment around $M$. viridis burrows $\left(2.1 \pm 0.5 \mathrm{~cm}^{3}\right)$ is small compared to the similar-sized Nereis diversicolor which typically reach oxic sediment volumes of $\sim 5.0 \mathrm{~cm}^{3}$ (Pischedda et al. 2008, 2012). However, the calculated sediment $\mathrm{O}_{2}$ uptake per burrow (45.6 \pm

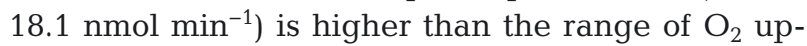
take per burrow of $N$. diversicolor from 8.7 to $22 \mathrm{nmol}$ $\min ^{-1}$ (derived from Banta et al. 1999, Nielsen et al. 2004, Papaspyrou et al. 2010, Kristensen et al. 2011). Higher sediment $\mathrm{O}_{2}$ uptake in the smaller volume of oxic sediment around the $M$. viridis burrows clearly indicates intensified biogeochemical activity near the burrow. Replacement of native $N$. diversicolor with similar-sized $M$. viridis would therefore lead to a significant decrease in volume of oxidized sediment with more intensified biogeochemistry.

The average integrated $\mathrm{O}_{2}$ consumption within the burrow and the surrounding sediment for the 3 investigated specimens amounted to $45.6 \pm 18.1 \mathrm{nmol}$ $\min ^{-1}$. Previous estimates on weight-specific $\mathrm{O}_{2}$ respiration by Marenzelleria viridis individuals of similar size to those used here are $26.5 \mathrm{nmol} \mathrm{g}_{\text {(wet wt) }}{ }^{-1}$ $\min ^{-1}$ (Quintana et al. 2007), corresponding to an

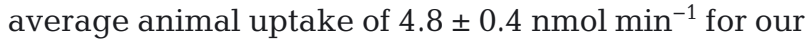

3 investigated specimens. The total $\mathrm{O}_{2}$ consumption per burrow, including the worm, thereby amounts to $50.4 \pm 18.5 \mathrm{nmol} \mathrm{min}{ }^{-1}$, of which $90 \%$ is related to uptake in the surrounding sediment. Since this assessment does not account for reduced solutes released to the overlying water that subsequently are oxidized, the burrow $\mathrm{O}_{2}$ uptake must therefore be regarded as a minimum of the total burrow impact. $M$. viridis burrow contribution to the total sediment uptake was estimated to be $87 \pm 32 \mathrm{mmol} \mathrm{m}^{-2} \mathrm{~d}^{-1}$, which compares well with rates of $63 \pm 6 \mathrm{mmol} \mathrm{m}^{-2} \mathrm{~d}^{-1}$ obtained from traditional core incubation experiments at similar worm densities (Quintana et al. 2013).

The complex $\mathrm{O}_{2}$ dynamics within and around Marenzelleria viridis burrows induce a unique microenvironment that favors meiofauna and microbial communities tolerant to oxic-anoxic oscillations (Urban-Malinga et al. 2013). This requires either versatile metabolic pathways or the ability to migrate with the pulsing oxic-anoxic interface. Furthermore, the proximity of oxic and sulfidic conditions in space and time may facilitate the growth of sulfide-oxidizing bacteria, like Beggiatoa, as previously observed in $M$. viridis burrow environments (Quintana et al. 2007, 2011, Kristensen et al. 2011). The resolved $\mathrm{O}_{2}$ dynamics may also have implication for nitrogen transformations within and around the burrow (Aller 1994, Kristensen et al. 2011). Ammonia released by mineralization and excreted by $M$. viridis will be effectively transported to the sediment-water interface by upward porewater percolation during ciliary pumping or out of the burrow during muscular pumping (Hietanen et al. 2007). Consequently, intensified nitrification may occur in the oscillating oxic zone surrounding the burrow opening, particularly during oxic expansion following periods of upward porewater transport. The extent of nitrification at the primary interface, however, will be dependent on the metabolic kinetics and sulfide sensitivity of the nitrifying microbial communities (Bonaglia et al. 2013). The complex oxic-anoxic dynamics may also affect denitrification and coupled nitrification-denitrification potentials in the surrounding sediment, as has been observed for other infauna species (Kristensen 1988, Pelegri et al. 1994, Pelegri \& Blackburn 1995). Likewise, oxic-anoxic oscillations may have implications for iron-sulfur-phosphorus dynamics (Fenchel \& Glud 2000), which in turn can regulate levels of bioavailable phosphorus (Hietanen et al. 2007, Bonaglia et al. 2013). These effects remain to be studied, but the novel insight into $\mathrm{O}_{2}$ variability now allows for more controlled and detailed investigations of the associated biogeochemistry. 
Acknowledgements. We acknowledge financial support from the Faculty of Science at the University of Southern Denmark, the Danish Council for Independent Research (FNU-12-125843, DNRF53), European Research Council Advanced Grants (ERC-2010-AdG-20100224) and the Commission for Scientific Research in Greenland (GCRC6507). Additionally, we thank A. Glud for help and support during preparation and execution of the experiments.

\section{LITERATURE CITED}

> Aller RC (1994) Bioturbation and remineralization of sedimentary organic matter: effects of redox oscillations. Chem Geol 114:331-345

> Banta GT, Holmer M, Jensen MH, Kristensen E (1999) Effects of two polychaete worms, Nereis diversicolor and Arenicola marina, on aerobic and anaerobic decomposition in a sandy marine sediment. Aquat Microb Ecol 19:189-204

> Bastrop R, Blank M (2006) Multiple invasions-a polychaete genus enters the Baltic Sea. Biol Invasions 8:1195-1200

- Bochert A, Richard D, Bochert R (1997) Marenzelleria cf. viridis and the sulphide regime. Aquat Ecol 31:223-231

Bonaglia S, Bartoli M, Gunnarsson JS, Rahm L and others (2013) Effect of reoxygenation and Marenzelleria spp. bioturbation on Baltic Sea sediment metabolism. Mar Ecol Prog Ser 482:43-55

> Borisov SM, Klimant I (2007) Ultrabright oxygen optodes based on cyclometalated iridium (iii) coumarin complexes. Anal Chem 79:7501-7509

- Carreira C, Larsen M, Glud RN, Brussaard CPD, Middelboe M (2013) Heterogeneous distribution of prokaryotes and viruses at the microscale in a tidal sediment. Aquat Microb Ecol 69:183-192

> Dauer DM, Maybury CA, Ewing RM (1981) Feeding behavior and general ecology of several spionid polychaetes from the Chesapeake Bay. J Exp Mar Biol Ecol 54:21-38

> Delefosse M, Banta GT, Canal-Verges P, Penha-Lopes G, Quintana CO, Valdemarsen T, Kristensen E (2012) Macrobenthic community response to the Marenzelleria viridis (Polychaeta) invasion of a Danish estuary. Mar Ecol Prog Ser 461:83-94

Essink K, Kleef HL (1988) Marenzelleria viridis (Verril, 1873) (Polychaeta: Spionidae): a new record from the Ems estuary (the Netherlands/Federal Republic of Germany). Zool Bijdr Leiden 38:1-13

Fenchel T, Glud RN (2000) Benthic primary production and $\mathrm{O}_{2}-\mathrm{CO}_{2}$ dynamics in a shallow-water sediment: spatial and temporal heterogeneity. Ophelia 53:159-171

> Frederiksen MS, Glud RN (2006) Oxygen dynamics in the rhizosphere of Zostera marina: a two-dimensional planar optode study. Limnol Oceanogr 51:1072-1083

George JD (1966) Reproduction and early development of the spionid polychaete, Scolecolepides viridis (Verrill). Biol Bull 130:76-93

> Glud RN (2008) Oxygen dynamics of marine sediments. Mar Biol Res 4:243-289

> Glud RN, Ramsing NB, Gundersen JK, Klimant I (1996) Planar optrodes: a new tool for fine scale measurements of two-dimensional $\mathrm{O}_{2}$ distribution in benthic communities. Mar Ecol Prog Ser 140:217-226

Hahlbeck E, Arndt C, Schiedek D (2000) Sulphide detoxification in Hediste diversicolor and Marenzelleria viridis, two dominant polychaete worms within the shallow coastal waters of the southern Baltic Sea. Comp Biochem
Physiol B 125:457-471

Hietanen S, Laine AO, Lukkari K (2007) The complex effects of the invasive polychaetes Marenzelleria spp. on benthic nutrient dynamics. J Exp Mar Biol Ecol 352:89-102

> Holst G, Grunwald B (2001) Luminescence lifetime imaging with transparent oxygen optodes. Sens Actuators B Chem 74:78-90

> Holst G, Kohls O, Klimant I, König B, Kühl M, Richter T (1998) A modular luminescence lifetime imaging system for mapping oxygen distribution in biological samples. Sens Actuators B Chem 51:163-170

> Huettel M, Gust G (1992) Solute release mechanisms from confined sediment cores in stirred benthic chambers and flume flows. Mar Ecol Prog Ser 82:187-197

Jensen KR, Knudsen J (2005) A summary of alien marine benthic invertebrates in Danish waters. Oceanol Hydrobiol Stud 34:137-162

Khalil GE, Chang A, Gouterman M, Callis JB, Dalton LR, Turro NJ, Jockusch S (2005) Oxygen pressure measurement using singlet oxygen emission. Rev Sci Instrum 76:1-8

Klimant I, Meyer V, Kühl M (1995) Fiber-optic oxygen microsensor, a new tool in aquatic biology. Limnol Oceanogr 40:1159-1165

Kristensen E (1988) Benthic fauna and biogeochemical processes in marine sediments: microbial activities and fluxes. In: Blackburn TH, Sørensen J (eds) Nitrogen cycling in coastal marine environments. John Wiley \& Sons, Chichester, p 275-299

Kristensen E (2001) Impact of polychaetes (Nereis spp. and Arenicola marina) on carbon biogeochemistry in coastal marine sediments. Geochem Trans 2:92-104

Kristensen E, Hansen T, Delefosse M, Banta GT, Quintana CO (2011) Contrasting effects of the polychaetes Marenzelleria viridis and Nereis diversicolor on benthic metabolism and solute transport in sandy coastal sediment. Mar Ecol Prog Ser 425:125-139

Larsen M, Borisov SM, Grunwald B, Klimant I, Glud RN (2011) A simple and inexpensive high resolution color ratiometric planar optode imaging approach. Limnol Oceanogr Methods 9:346-358

> Mayr T, Borisov SM, Abel T, Enko B, Waich K, Mistlberger G, Klimant I (2009) Light harvesting as a simple and versatile way to enhance brightness of luminescent sensors. Anal Chem 81:6541-6545

McLusky DS, Hull SC, Elliott M (1993) Variations in the intertidal and subtidal macrofauna and sediments along a salinity gradient in the upper Forth Estuary. Neth J Aquat Ecol 27:101-109

Meysman FJR, Galaktionov OS, Gribsholt B, Middelburg JJ (2006) Bio-irrigation in permeable sediments: advective pore water transport induced by burrow ventilation. Limnol Oceanogr 51:142-156

Meysman FJR, Galaktionov OS, Glud RN, Middelburg JJ (2010) Oxygen penetration around burrows and roots in aquatic sediments. J Mar Res 68:309-336

> Nielsen OI, Gribsholt B, Kristensen E, Revsbech NP (2004) Microscale distribution of oxygen and nitrate in sediment inhabited by Nereis diversicolor: spatial patterns and estimated reaction rates. Aquat Microb Ecol 34:23-32

> Oguri K, Kitazato H, Glud RN (2006) Platinum octaetylporphyrin based planar optodes combined with an UV-LED excitation light source: an ideal tool for high-resolution $\mathrm{O}_{2}$ imaging in $\mathrm{O}_{2}$ depleted environments. Mar Chem 100: 95-107

Papaspyrou S, Thessalou-Legaki M, Kristensen E (2010) The 
influence of infaunal (Nereis diversicolor) abundance on degradation of organic matter in sandy sediments. J Exp Mar Biol Ecol 393:148-157

Pelegri SP, Blackburn TH (1995) Effect of bioturbation by Nereis sp., Mya arenaria and Cerastoderma sp. on nitrification and denitrification in estuarine sediments. Ophelia 42:289-299

Pelegri SP, Nielsen LP, Blackburn TH (1994) Denitrification in estuarine sediment stimulated by the irrigation activity of the amphipod Corophium volutator. Mar Ecol Prog Ser 105:285-290

Pischedda L, Poggiale JC, Cuny P, Gilbert F (2008) Imaging oxygen distribution in marine sediments. The importance of bioturbation and sediment heterogeneity. Acta Biotheor 56:123-135

Pischedda L, Cuny P, Esteves JL, Poggiale JC, Gilbert F (2012) Spatial oxygen heterogeneity in a Hediste diversicolor irrigated burrow. Hydrobiologia 680:109-124

Quintana CO, Tang M, Kristensen E (2007) Simultaneous study of particle reworking, irrigation transport and reaction rates in sediment bioturbated by the polychaetes Heteromastus and Marenzelleria. J Exp Mar Biol Ecol 352:392-406

Quintana CO, Hansen T, Delefosse M, Banta G, Kristensen E (2011) Burrow ventilation and associated porewater irrigation by the polychaete Marenzelleria viridis. J Exp Mar Biol Ecol 397:179-187

Quintana CO, Kristensen E, Valdemarsen T (2013) Impact of the invasive polychaete Marenzelleria viridis on the biogeochemistry of sandy marine sediments. Biogeochemistry 115:95-109

Editorial responsibility: Martin Solan, Southampton, UK
Rodriguez E, Giacomelli F, Vazquez A (2004) Permeabilityporosity relationship in RTM for different fiberglass and natural reinforcements. J Compos Mater 38:259-268

Santos IR, Eyre BD, Huettel M (2012) The driving forces of porewater and groundwater flow in permeable coastal sediments: a review. Estuar Coast Shelf Sci 98:1-15

> Schiedek D (1997) Marenzelleria viridis (Verrill, 1873) (Polychaeta), a new benthic species within European coastal waters. Some metabolic features. J Exp Mar Biol Ecol 211:85-101

Schiedek D, Vogan C, Hardege J, Bentley M (1997) Marenzelleria cf. wireni (Polychaeta: Spionidae) from the Tay Estuary. Metabolic response to severe hypoxia and hydrogen sulphide. Aquat Ecol 31:211-222

Smart PL, Laidlaw IMS (1977) An evaluation of some fluorescent dyes for water tracing. Water Resour Res 13: 15-33

> Urban-Malinga B, Warzocha J, Zalewski M (2013) Effects of the invasive polychaete Marenzellaria spp. on benthic processes and meiobenthos of a species-poor brackish system. J Sea Res 80:25-34

> Volkenborn N, Polerecky L, Wethey DS, Woodin SA (2010) Oscillatory porewater bioadvection in marine sediments induced by hydraulic activities of Arenicola marina. Limnol Oceanogr 55:1231-1247

Wenzhöfer F, Glud RN (2004) Small-scale spatial and temporal variability in coastal benthic $\mathrm{O}_{2}$ dynamics: effects of fauna activity. Limnol Oceanogr 49:1471-1481

Woodin SA, Wethey DS, Volkenborn N (2010) Infaunal hydraulic ecosystem engineers: cast of characters and impacts. Integr Comp Biol 50:176-187

Submitted: September 4, 2013; Accepted: January 20, 2014 Proofs received from author(s): March 28, 2014 